Int. J. Morphol.,

30(4):1512-1519, 2012

\title{
Desarrollo de los Miembros en los Vertebrados
}

\author{
Limb Development in Vertebrates
}

"Marcelo Antonelli; ** Carlos Rosas \& ${ }^{* *}$ Mariana Rojas

ANTONELLI, M.; ROSAS, C. \& ROJAS, M. Desarrollo de los miembros en los vertebrados. Int. J. Morphol., 30(4):1512-1519, 2012.

RESUMEN: Los miembros de los vertebrados son estructuras complejas con tres ejes a considerar, proximal-distal, anteriorposterior y dorsal-ventral. La batería de genes involucrados en la formación de estas estructuras está bastante conservada en la evolución. El esbozo del miembro está compuesto de células mesenquimáticas indiferenciadas que derivan del mesodermo lateral somático cubiertas por ectodermo. La cresta apical ectodérmica es un centro productor de señales para el desarrollo y se ubica en el margen distal del esbozo de miembro. La zona de progreso esta a continuación y permite el crecimiento del miembro. El tipo de estructuras formadas a lo largo del eje proximal distal es especificado por los genes Hox. La proteína Sonic Hedgehog está involucrada en la regulación de la actividad de un segundo centro de señales conocido como zona de actividad polarizante. Los miembros también tienen una polaridad dorso ventral. La proteína WNT7A secretada desde el ectodermo dorsal, instruye a las células mesenquimales circundantes a diferenciarse en estructuras dorsales mientras que Engrailed 1 expresado en el ectodermo ventral, inhibe la expresión de WNT7A en esta zona del esbozo de miembro promoviendo la formación de estructuras ventrales.

PALABRAS CLAVE: Miembros; Cresta apical; Zona de progreso; Zona de actividad polarizante; Raya.

\section{INTRODUCCIÓN}

Dada la importancia que tienen los miembros en el proceso de locomoción y el grado de conservación que muestran estas estructuras a lo largo de la evolución de los vertebrados, se considera hoy en día relevante entender su desarrollo en los vertebrados en diferentes modelos animales comparando los genes involucrados en este proceso y los fenómenos celulares observados en las distintas especies estudiadas.

Desarrollo de los miembros en vertebrados. Los miembros de los vertebrados son órganos complejos con un arreglo asimétrico de sus partes. Existen tres ejes a considerar, el primero de los cuales es el eje proximal-distal, el segundo eje es el anterior-posterior y el tercer eje es el dorsal-ventral (dorso y palma de la mano). Este sistema ha sido estudiado simultáneamente en ratón, pollo y pez cebra y aunque el resultado final del proceso es diferente en las distintas especies, la batería de genes involucrados en la formación de estas estructuras está bastante conservada en la evolución. Además, a nivel morfológico el proceso de formación durante el desarrollo temprano de los miembros es similar en todos los vertebrados (Hinchliffe, 2002).

\section{Especificación e inducción del esbozo de miembro.}

Ácido Retinoico y genes Hox. La señal molecular que le indica al embrión de vertebrado la posición exacta desde donde deben desarrollar los esbozo de los miembros está dada por el ácido retinoico y los productos proteicos de los genes Hox. El ácido retinoico que actúa a modo de morfógeno, es producido en la región posterior del embrión difundiendo hacia la región anterior generando un gradiente de concentración que determina la expresión de genes homeóticos de la familia Hox en aquellas posiciones donde posteriormente se formarán los miembros anteriores y posteriores (ó superiores e inferiores). La expresión específica de los genes Hox (HoxA y HoxD) en estas posiciones es fundamental para la posterior formación de los esbozo de los miembros en el embrión de vertebrado (Kmita, 2005).

$\boldsymbol{F} \boldsymbol{g} \boldsymbol{f}$ y $\boldsymbol{W n t}$. Aquellos segmentos del mesodermo embrionario desde donde se derivan los miembros, quedan especificados mucho antes de que aparezcan los esbozos de miembros debido a la acción de los genes Hox. Esta especificación se debe a la expresión regional de ciertos genes de la

* Laboratorio de Biología Molecular del Desarrollo. Programa de Biología Celular y Molecular. Instituto de Ciencias Biomédicas. Facultad de Medicina. Universidad de Chile.

*** Laboratorio de Embriología Comparada. Programa de Anatomía y Biología del Desarrollo. Instituto de Ciencias Biomédicas. Facultad de Medicina. Universidad de Chile. 
familia de Fgf (factor de crecimiento fibroblástico) y de Wnt. Estas proteínas difunden desde las células que los producen formando un gradiente de concentración que disminuye con la distancia desde su centro de producción, y el cual tiene una acción biológica diferencial en los distintos tejidos blancos sobre las que actúa (Kawakami, 2001).

Una proteína codificada por un miembro de la familia de genes Fgf, FGF10 es fundamental en la formación de los miembros. Esta proteína es producida por las células mesenquimales del mesodermo lateral somático a partir del cual posteriormente se forman los miembros. FGF10 es capaz de promover mediante un efecto paracrino las interacciones mesodermoectodermo que llevan a la formación de los miembros (Gilbert, 2006). Este efecto paracrino de FGF10 se traduce en dos efectos en la zona donde se formarán los miembros:

1) La proliferación de las células mesenquimales del mesodermo lateral somático que conduce a la formación del esbozo de miembro.

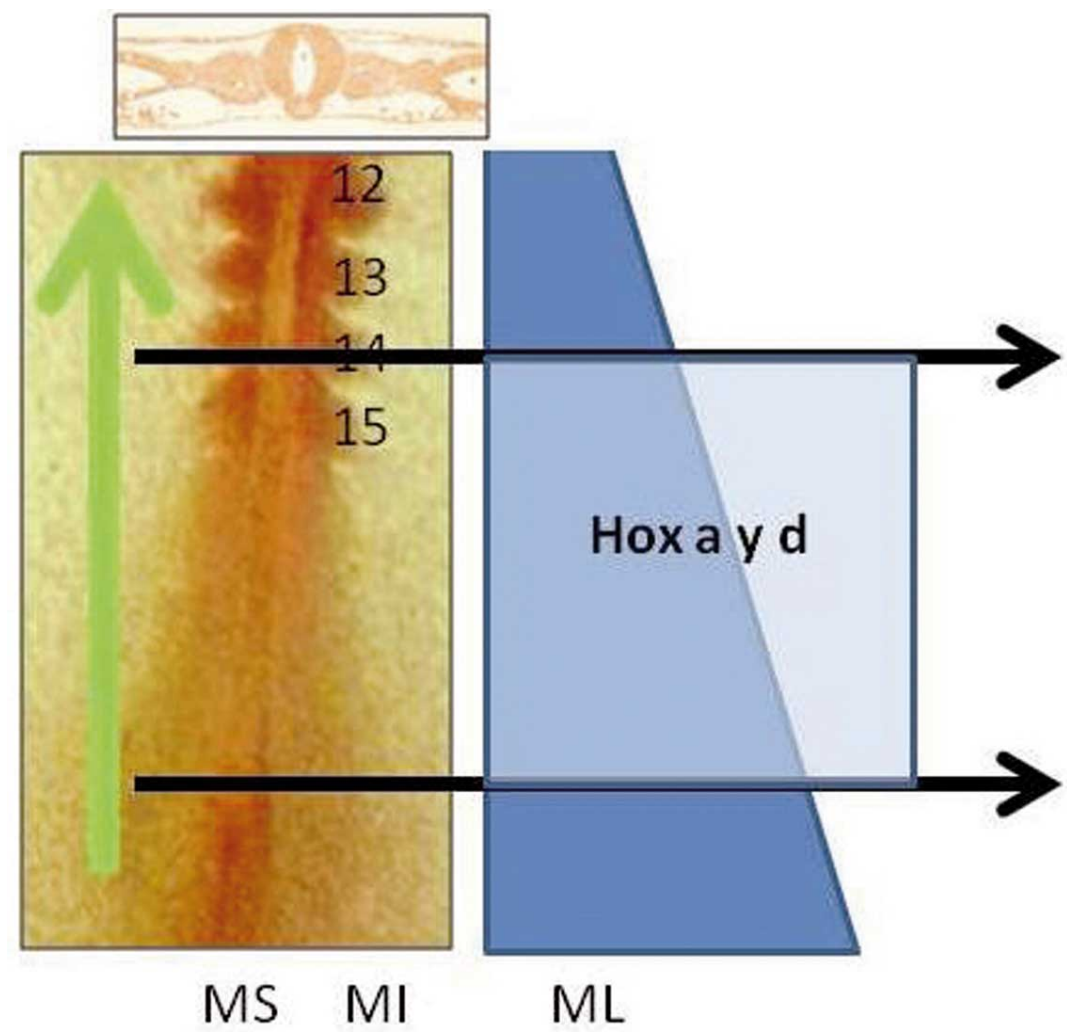

Fig. 1. Especificación del miembro superior en el embrión de pollo. El gradiente de ácido retinoico, cuya concentración disminuye hacia anterior (flecha verde), determina la expresión de los genes Hox a y Hox d en la zona del mesodermo lateral limitado por las dos flechas. La expresión de estos dos genes determina la zona del mesodermo lateral desde donde posteriormente se van a formar los miembros. El color azul indica la expresión en gradiente del ácido retinoico. El color celeste muestra la zona donde se expresen los genes HoxA y HoxD. MS: mesodermo somítico, MI: mesodermo intermedio, ML: mesodermo lateral. 12,13, 14 y 15: número ordinal de somitos. En el recuadro superior se observa un corte transversal de embrión de pollo.
2) Induce la expresión de la proteína FGF8 en el ectodermo adyacente al mesodermo lateral. Esta expresión es importante en la generación de los miembros.

La expresión de FGF10 es previamente promovida y luego mantenida por miembros de la familia Wnt en la zona donde se formarán los miembros anteriores y posteriores (Kawakami).

Hasta ahora hemos básicamente explicado como se especifican los miembros. Sin embargo surge la pregunta de cómo los vertebrados pueden distinguir entre generar miembros anteriores y posteriores. La respuesta a esta pregunta parece estar centrada en dos factores de transcripción $T b x 5$ y $T b x 4$ cuya expresión tanto a nivel de mRNA y de proteína está restringida al mesodermo lateral adyacente a las zonas de formación de los esbozo de miembros anteriores y posteriores respectivamente. Experimentos de pérdida de la función de $T b x 5$ y $T b x 4$, producen embriones sin los miembros anteriores y posteriores, respectivamente. Ambos genes inducen y mantienen la expresión de FGF10 en el mesodermo lateral adyacente al ectodermo desde donde se formarán los miembros tanto superiores como posteriores. A su vez, la expresión de $T b x 5$ y $T b x 4$ es promovida por distintos miembros de la familia de proteínas Wnt (Krause, 2004).

Formación de los esbozos de miembros. Según Shum et al. (2003), el esbozo de el miembro está compuesto de células mesenquimáticas indiferenciadas que derivan del mesodermo lateral somático y están cubiertos por ectodermo. Según Montero \& Hurlé (2007) esta condensación de células mesenquimáticas está mediado por moléculas como Fibronectina, N-Cadherina, Tenascina y Proteína Oligomérica de Cartílago y la disminución de Colágeno tipo I. Una vez que el mesodermo lateral somático ha sido inducido por la acción de FGF10, estas células mesenquimales comienzan a proliferar y forman los esbozos embrionarios de los miembros (Fig. 2). Paralelamente otras 


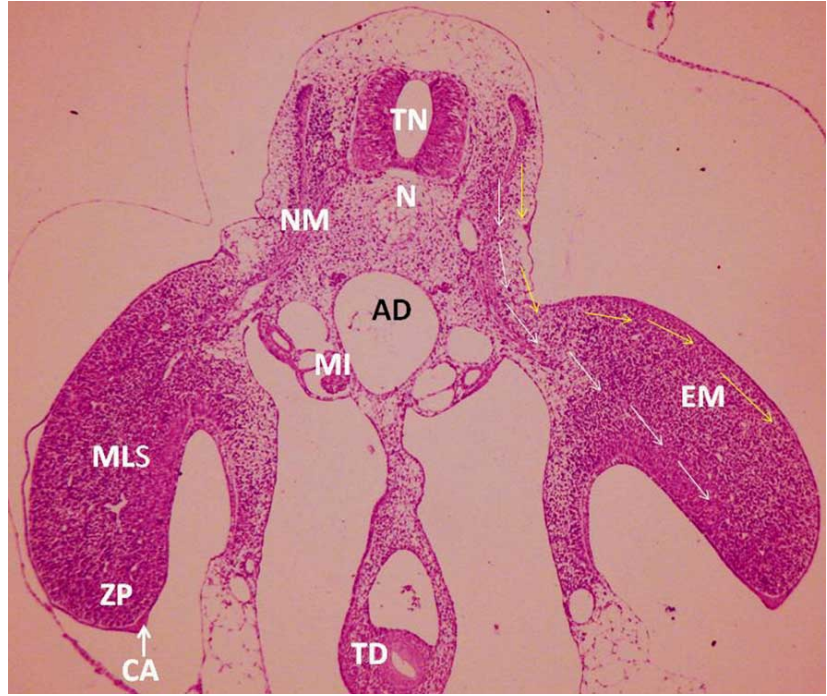

Fig. 2. Migración de células mesenquimales desde el dermatomo y miotomo lateral de los somitos. Una vez que estas células llegan al esbozo de miembro, se diferencian en dermis y músculo estriado, las células del mesodermo lateral somático, en cambio, formarán huesos y cartílagos. Se observan esbozos de miembros (EM) originados desde el mesodermo lateral somático (MLS), la zona de progreso (ZP) y la cresta apical ectodérmica (CA). fibras nerviosas $\mathrm{NM}$, tubo neural $(\mathrm{TN})$, notocorda $(\mathrm{N})$, aorta dorsal $(\mathrm{AD})$, mesodermo intermedio (MI), tubo digestivo (TD). Corte transversal de embrión de pollo, 72 horas de incubación. HematoxilinaEosina 400X.

células como las del dermatomo y miotomo lateral migran desde el somito hacia la zona del esbozo de miembro y esta comienza a crecer en tamaño formando el miembro (Carlson, 2009) (Fig. 3). Este fenómeno ocurre tanto en los miembros anteriores (superiores) como en los posteriores (inferiores).

Inducción y formación de la cresta apical ectodérmica . Cuando las células mesenquimales ingresan en la región de el miembro, secretan factores que inducen al ectodermo que la recubre a formar la llamada cresta apical ectodérmica (CAE) (Gilbert). Esta estructura se ubica en el margen distal del esbozo de miembro (Fig. 4) y se constituye en un centro productor de señales para el desarrollo de ellas. La función de la CAE incluye:

1) Mantener el tejido mesenquimal ubicado bajo él en un estado de proliferación continua que permite el crecimiento del miembro en la dirección proximal distal.

2) Mantener la expresión de moléculas que permiten la formación del eje antero posterior del miembro.

3) Interactuar con proteínas que especifican los ejes antero posterior y dorso ventral de manera que cada célula reciba la información posicional necesaria para diferenciarse.

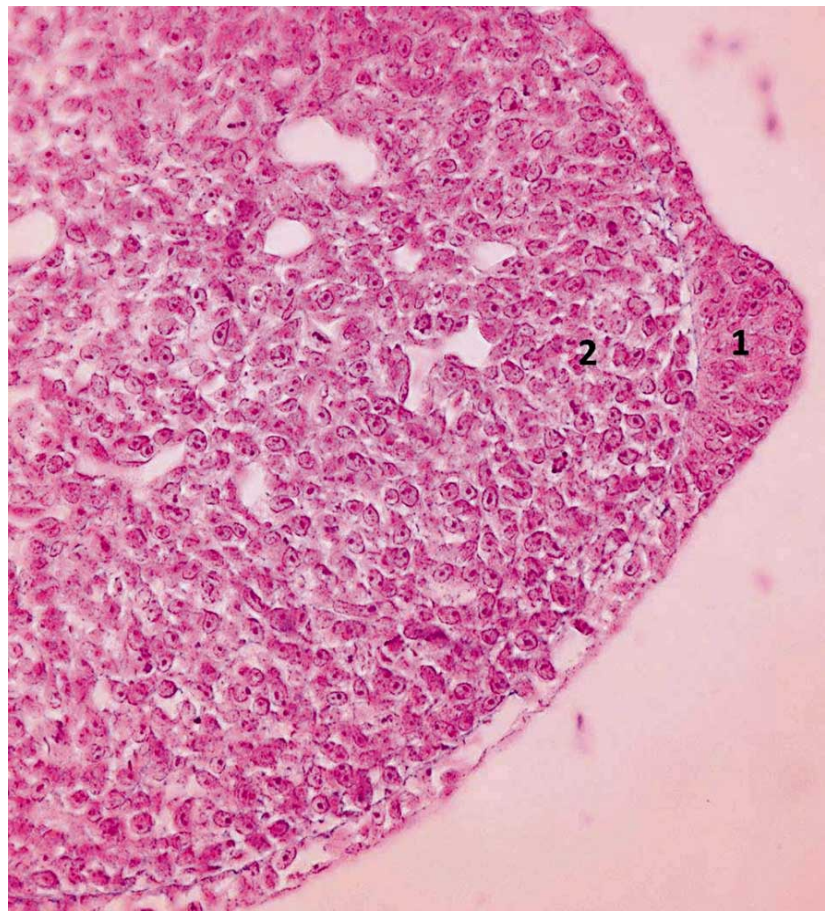

Fig. 3. Cresta apical ectodérmica (1), zona de progreso (2) Embrión de pollo de 72 hs de incubación, Hematoxilina-Eosina, 400X.

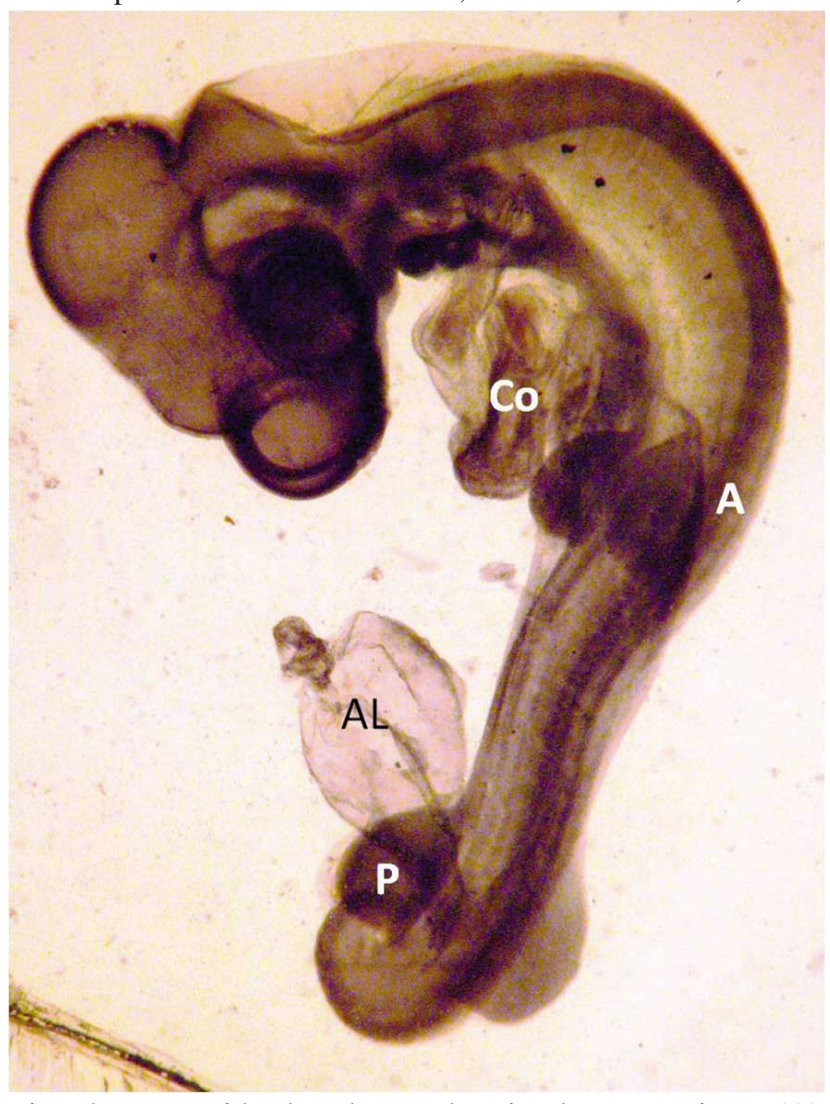

Fig. 4. Formación de esbozos de miembros anteriores (A) y posteriores $(\mathrm{P})$, corazón $(\mathrm{Co})$, alantoides $(\mathrm{AL})$. Embrión de pollo in toto de 72 hs de incubación. 40X. 
Como resultado de las funciones de la CAE, el esbozo de el miembro crece debido a la proliferación de células mesenquimales que se encuentran inmediatamente bajo la CAE. El resultado neto de este proceso es el crecimiento progresivo de los miembros de los vertebrados. El factor secretado por las células mesenquimales que induce la formación de la CAE es FGF10. Esta proteína induce la formación de la CAE en el ectodermo que se encuentra en el límite entre los lados dorsales y ventrales del embrión (Ohuchi, 1997).

La cresta apical ectodérmica es a su vez la fuente de varios factores de crecimiento fibroblástico que mantienen la continua división del tejido mesenquimal que se encuentra bajo el CAE. Esta zona de activa proliferación celular recibe el nombre de zona de progreso (ZP). Una vez que las células mesenquimales dejan la ZP se diferencian específicamente de acuerdo a la posición que adquieren en ese momento. De esta manera se define el eje proximal-distal en la formación de los miembros anteriores y posteriores en vertebrados (Gilbert).

Cuando las células mesenquimales dejan la zona de progreso, ellas se diferencian de una manera "regionalmente especifica". Esto implica que las primeras células en dejar la ZP formaran estructuras proximales, (como por ejemplo el húmero y el fémur) mientras que las células que han experimentado numerosas divisiones en la zona de progreso formarán estructuras más distales. El estado mitótico de la ZP es mantenido por interacciones entre proteínas de la familia FGF producidas en la zona de progreso y la CAE (Capdevila \& Ispizúa Belmonte, 2001). Como se mencionó anteriormente antes de la formación de la esbozo de miembro, las células mesenquimales del mesodermo lateral somático producen FGF10. Esta proteína secretada induce entonces a las células del ectodermo adyacente a producir FGF8. Una vez que el ectodermo se diferencia en la CAE por acción de FGF10, la producción de la proteína FGF8 por esta estructura se mantiene. La proteína FGF8 producida y secretada por la CAE mantiene la actividad mitótica de las células mesenquimales de la ZP. La expresión de FGF8 es a su vez necesaria para mantener la expresión de FGF10 en la ZP (Boulet, 2004).

\section{Especificación del eje proximal distal}

Genes Hox. El tipo de estructura formado a lo largo del eje proximal distal es especificado por los genes Hox. La función de los genes Hox ha sido ya analizada en la especificación del mesodermo donde los miembros se forman. Ellos cumplen una segunda función en la especificación de las células mesenquimales que forman las distintas porciones del eje proximal distal de los miembros en vertebrados (estilopodo, zeugopodo o autopodo). Los genes Hox involucrados en esta función son miembros de la familia HoxA y HoxD (Kmita). Como resultado de la acción de estos genes se forman tanto los miembros anteriores como las posteriores. El resultado final de esta acción génica difiere bastante en los distintos vertebrados.

\section{Especificación del eje antero-posterior}

\section{Formación de la zona de actividad polarizante}

Sonic hedgehog. La proteína FGF8 induce la expresión de otro gen cuya proteína también es capaz de difundir: Sonic hedgehog $(S h h)$. La proteína SHH está involucrada en la regulación de la actividad de un segundo centro de señales del esbozo de miembro, la zona de actividad polarizante (ZAP) (McGlinn \& Tabin, 2006). La ZAP ha sido relacionada con la especificación del eje antero-posterior de los miembros. Cuando el tejido que contiene la ZAP es tomado de un esbozo de miembro en desarrollo y es transplantada sobre el lado anterior de otro esbozo de miembro, el número de dígitos del miembro resultante se duplica. Sin embargo la estructura formada con el número extra de dígitos es la imagen especular de la estructura normalmente producida. SHH es la proteína que funciona como agente regulador de la actividad de la ZAP. Su expresión es fundamental en la formación del eje antero posterior de los miembros en vertebrados (Yang, 1997). La expresión de SHH en la zona de la actividad polarizante parece ser regulada por miembros de la familia de genes HoxA y HoxD (Kmita).

\section{Formación del eje proximal distal}

Shh. La actividad biológica de SHH es compleja, pues esta proteína induce además la expresión de FGF4 en la zona posterior del CAE. La secreción de FGF4 por el CAE es a su vez importante para mantener de manera reciproca la expresión de SHH en la ZAP. SHH además mantiene la expresión de FGF4 y FGF8 en el CAE. De esta manera SHH no solo regula la formación del eje antero-posterior como se describió anteriormente, sino que también es un factor importante en la formación del eje proximal distal de los miembros (McGlinn, \& Tabin).

Generación del eje dorso ventral. Los miembros tienen una polaridad dorso ventral. La especificación de este eje se debe a un tercer centro que reside en el ectodermo no apical. Este centro es el responsable de enviar señales generadoras de polaridad dorso-ventral sobre el mesénquima circundante. La proteína WNT7A secretada desde el ectodermo dorsal, instruye a las células mesenquimales circundantes a diferenciarse en estructuras dorsales mientras que Engrailed 1 expresado en el ectodermo ventral, inhibe la expresión de WNT7A en esta zona del esbozo de miembro promoviendo la formación de estructuras ventrales (Loomis, 1996). 


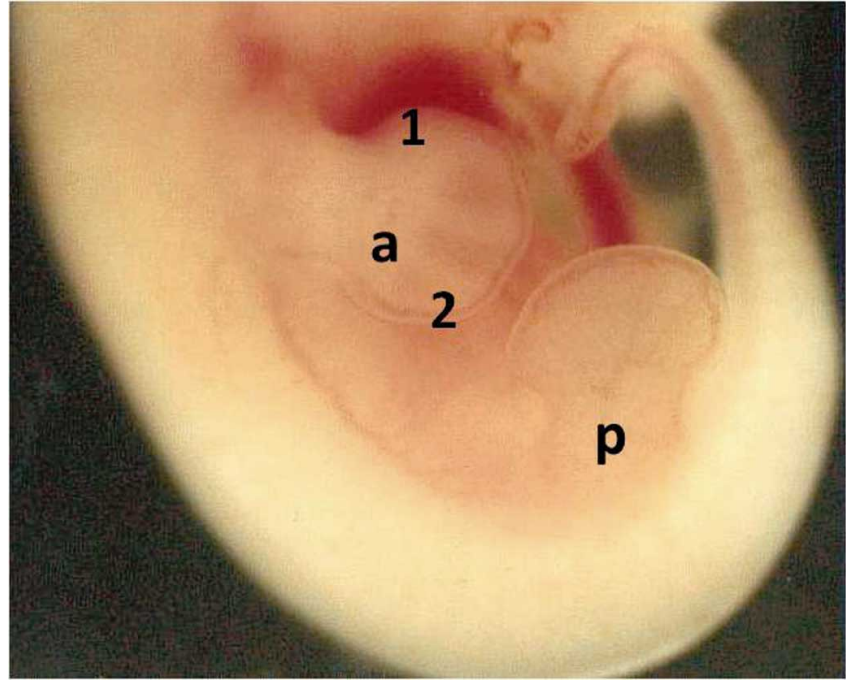

Fig. 5. Los miembros anteriores(a) están más avanzados que los posteriores (p). En los miembros anteriores se observa la diferenciación de los dedos y membranas interdigitales. También se puede reconocer el eje anteroposterior del miembro En la región anterior se formará el pulgar (1) y en la región posterior el dedo mínimo (2). Embrión de ratón de 12 ds de gestación.

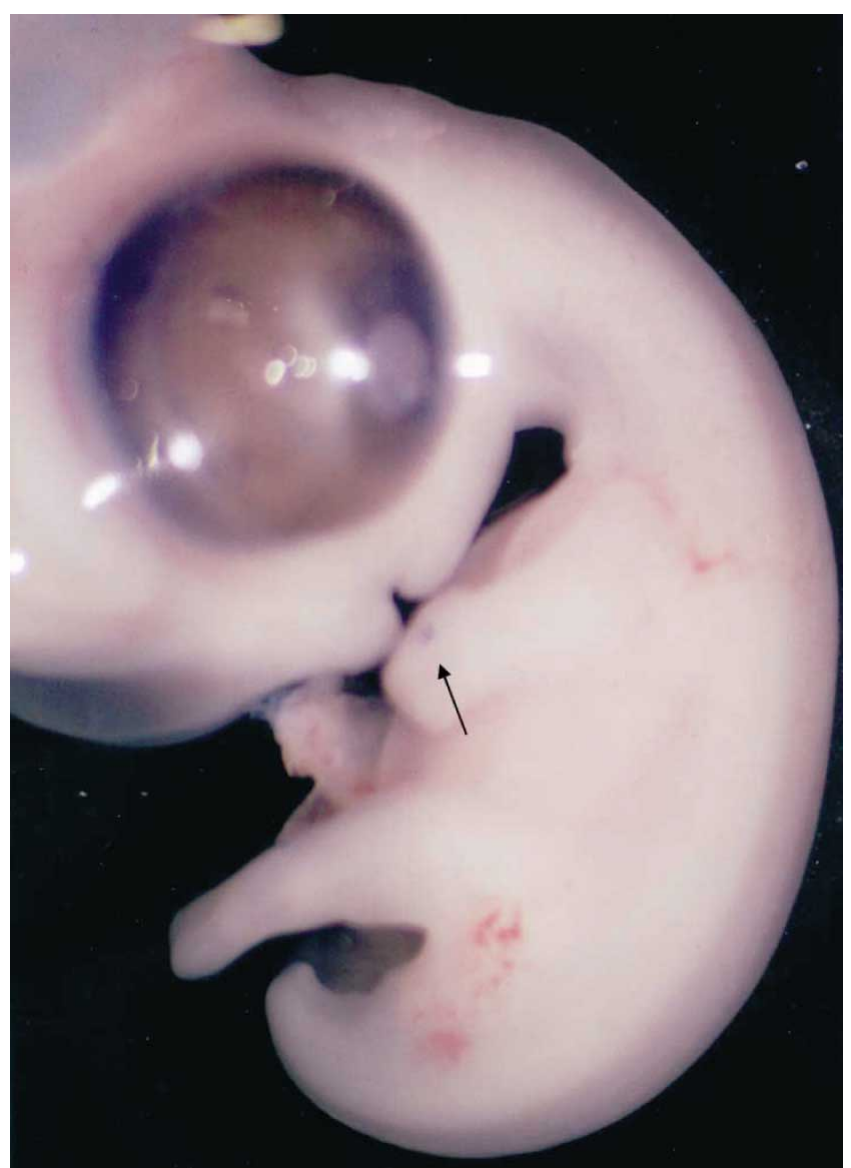

Fig. 6. La flecha indica apoptosis de la membrana interdigital destacada por la marca azul. Embrión de pollo de 120 horas de incubación.Tinción: Azul Tripán.
Formación de los dígitos de los miembros: muerte celular programada o apoptosis (Figs. 6 y 7) La muerte celular programada cumple una función fundamental en "esculpir" los miembros (Gilbert). Verdaderamente la apoptosis es fundamental en la formación de las articulaciones y en la formación de los dígitos separados (autópodo) que observamos en los vertebrados. La muerte de células específicas en los miembros de los vertebrados está genéticamente programada y ha sido seleccionada durante la evolución. Por ejemplo, el miembro inferior de un pollo y la de un pato muestran un patrón distinto de muerte celular entre los dígitos. Algunos experimentos han mostrado que en ciertos estadios del desarrollo del miembro inferior del pollo, las células ubicadas entre los dígitos del cartílago mueren y así lo hacen si son previamente transplantadas a otra región del embrión o son transferidas a un medio de cultivo. La señal molecular que promueve la apoptosis está mediada por proteínas de la familia de los factores morfogenéticas óseos o BMPs (por "Bone Morphogenetic Proteins") (Zeller, 2009).

Paralelo a esta etapa comienza el desarrollo de la matriz cartilaginosa y la formación de condrocitos, lo que finalmente llegará a ser reemplazado por hueso. Por su parte Gilbert considera la existencia de un patrón esquelético y que estaría compuesto por un estilópodo, que originará al húmero o fémur, un zeugópodo que representa al radio y ulna en el miembro anterior y tibia y peroné en el miembro posterior y un autópodo que origina el carpo y dedos de la mano en anterior y tarso y dedos del pie en posterior (Fig. 7).

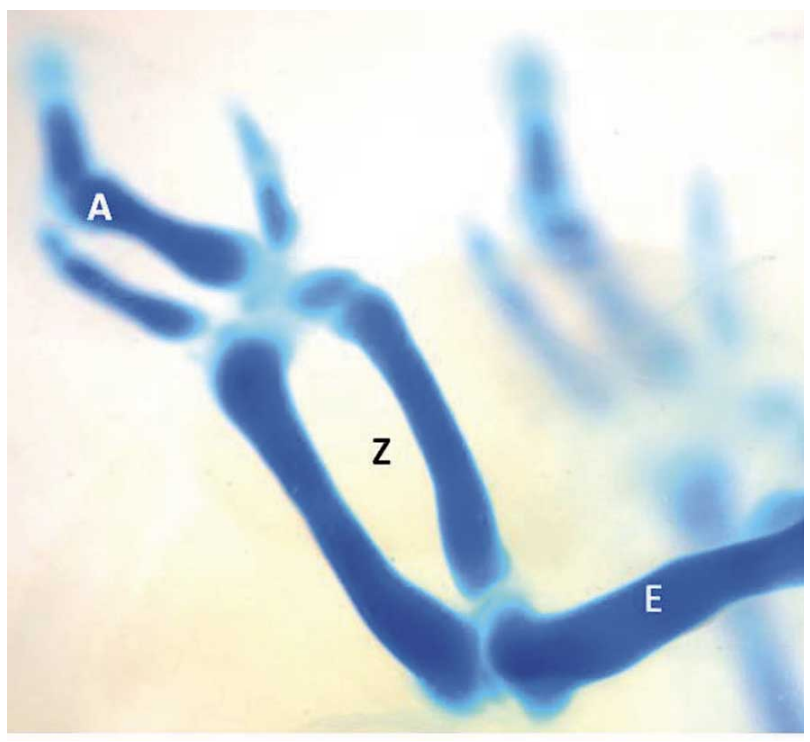

Fig. 7. Estilópodo (E), Zeugópodo (Z), Autópodo (A). Miembro anterior de embrión de pollo de 120 horas de incubación.Técnica de diafanización y tinción de cartílago según Hanken y Wassersug 16X. 
Coates (1995) y Zakany \& Duboule (2007) realizaron una comparación entre los miembros de los tetrápodos y las aletas de los teleósteos y observaron que el patrón de expresión de genes Hox era bastante similar en ellos, aun cuando sean dos estructuras funcionalmente diferentes. Nosotros hemos observado en embriones de raya (Fig. 8) la presencia de un esbozo de miembro similar al descrito para aves y mamíferos. Todas estas concordancias hace pensar en la existencia de una homología en estos organismos y que la existencia de una interacción celular y molecular provoca la diferenciación de esta extremidad que es propia de cada especie. Esto también se explica porque la forma y la función están íntimamenterelacionadas y las especies como las rayas no requieren una osificación en sus aletas.

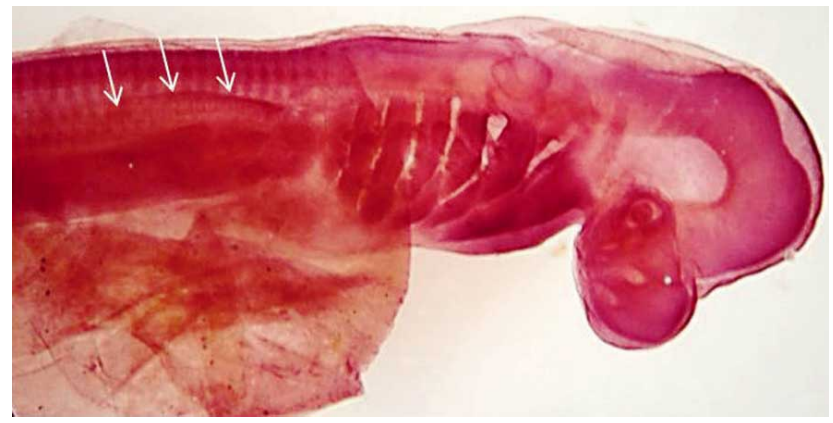

Fig. 8. A: Embrión de raya (condrictio). Las flechas indican el esbozo de miembro, 200 X. Tinción eosina.

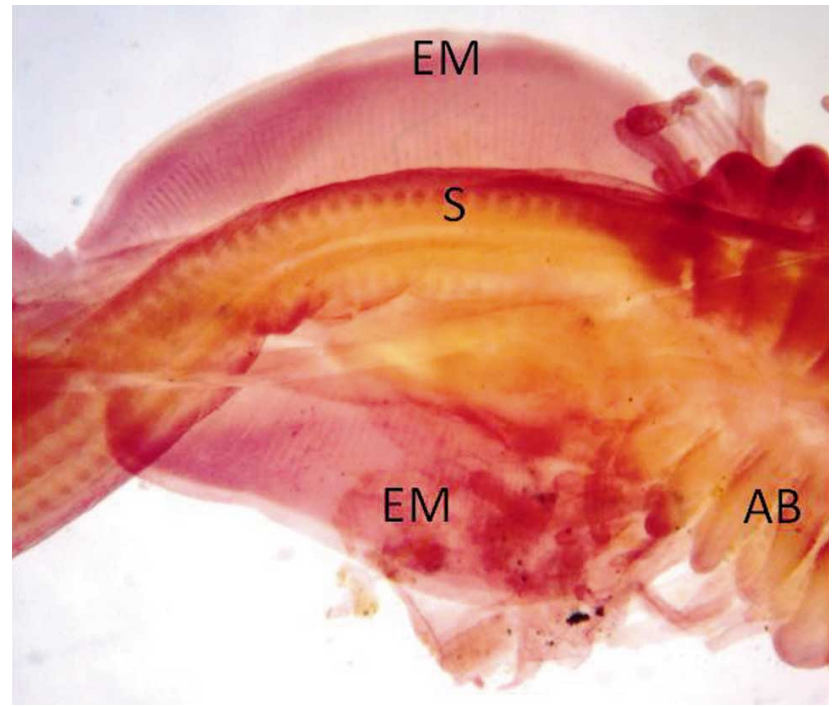

Fig. 8. B: Mayor desarrollo de aleta de raya Esbozo de miembro (EM) somitos (S), arcos branquiales (AB). 200X. Tinción eosina.

No obstante, los tetrápodos si sufrieron rápidos cambios en el esqueleto apendicular y que estuvieron fuertemente asociados a la locomoción terrestre. Muchos autores como Haines (2001) y Kardong (2005) concuerdan en que los cambios en el modelo primitivo de los miembros se correlacionan con cambios en la función, que surgen de los papeles biológicos en los que participan los miembros. Se cree que los Ripidistios tenían aletas carnosas y usaban sus aletas como puntos de apoyo. Esto, en algún momento influyó como presión selectiva, obligando a el miembro a calcificarse, desarrollar músculo, enrobustecerse y generar un miembro que le brindara apoyo. Una vez que los tetrápodos alcanzaran la tierra y se movilizaran, existieron muchas variaciones como es el caso de los tetrápodos primitivos como Icthyostega que tenían 7 dedos, aun cuando el patrón estándar es el modelo pentadáctilo. Esto nos hace pensar en alguna razón que haya obligado a perder algunos dedos. Se ha observado que muchas especies actuales tienen un número reducido de sus falanges, nuevamente por una razón funcional, la locomoción.

A simple vista es difícil intentar revelar por qué los Condrictios poseen aletas pectorales cartilaginosas. No obstante el estudio molecular, nos podría conducir a una explicación con más fundamento. Martin (2001) considera que el gen HoxD5 podría estar involucrado ya que si bien estuvo presente en los ancestros comunes de todos los vertebrados, se perdió este gen luego de la aparición de los Condrictios pero antes del origen de los Actinopterigios. Por su parte, Metscher et al. (2005) afirman que el patrón de expresión temprano en tetrápodos es similar a lo observado en el desarrollo tardío de las aletas y que la principal diferencia entre aletas y miembros radica en la expresión de los genes HoxA debido a que en tetrápodos la expresión de Hoxa11 es suprimida por Hoxal3 en el mesénquima del miembro distal. Por otra parte, la expresión de Shh podría dar luces del desarrollo de los miembros. Tanaka et al. (2002) plantean que el metapterigio, el principal hueso largo de la aleta, en algún momento de la evolución tuvo que rotar hacia fuera del cuerpo, cambiando la orientación de éste y generando el miembro, siendo $S h h$ un factor fundamental en el proceso y que en el desarrollo de las aletas de Condrictios estaba ausente. Dahn et al. (2007) creen que los Condrictios si comparten un patrón de expresión de $S h h$ a nivel apendicular y que algunos aspectos de la función de Shh son profundamente conservados en la filogenia de los Vertebrados, concluyendo finalmente que la regulación de la expresión de $S h h$ por Ácido Retinoico es probablemente la condición primitiva para todos los esqueletos apendiculares de los vertebrados.

Finalmente podemos concluir que existe un patrón de desarrollo común en la formación del esqueleto apendicular de los vertebrados, aun cuando existen diferencias en la composición de su esqueleto. Todas las especies estudiadas comienzan la formación de los miembros con una condensación celular ventrolateral par. Posteriormente los 
Condrictios y el resto de los Vertebrados desarrollan diferencias que le son propias para realizar sus funciones biológicas y que han sido desplegadas a lo largo de la evolución de las especies, ya sea reduciendo su número de falanges, cambiando el punto de apoyo o aligerando el peso de los huesos. No obstante al observar cómo se forman los miembros vemos que existen homologías embrionarias dentro del sub-filum Vertebrata y que esto sin duda puede aportar información para explicar el desarrollo de los miembros en las especies.

ANTONELLI, M.; ROSAS, C. \& ROJAS, M. Limb development in vertebrates. Int. J. Morphol., 30(4):1512-1519, 2012.

SUMMARY: Members of vertebrates are complex structures with three lines to consider, proximal-distal, anterior-posterior and dorsal-ventral. The battery of genes involved in the formation of these structures is well conserved in evolution. The outline of the member is composed of undifferentiated mesenchymal cells derived from somatic lateral mesoderm covered by ectoderm. The apical ectodermal ridge is a signal producing center for development and is located in the distal margin of the outline of a member. The area of progress is below and allows the growth of the member. The type of structures formed along the proximal distal axis is specified by Hox genes. Sonic Hedgehog protein is involved in regulating the activity of a second signaling center known as the zone of polarizing activity. Members also have a dorsal ventral polarity. The Wnt protein secreted from the dorsal ectoderm, instructs the surrounding mesenchymal cells to differentiate into dorsal structures whereas Engrailed 1 expressed in the ventral ectoderm, inhibit the expression of WNT7A outline in this membership area promoting the formation of ventral structures.

KEY WORDS: Limbs; Apical ridge; Progress zone; Polarizing activity zone; Raya.

\section{REFERENCIAS BIBLIOGRÁFICAS}

Boulet, A. M.; Moon, A.; Arenkiela, B. R. \& Capecchi, M. R. The roles of Fgf4 and Fgf8 in limb bud initiation and outgrowth. Dev. Biol., 273:361-72, 2004.

Capdevila, J. \& Izpisúa Belmonte, J. C. Patterning mechanisms controlling vertebrate limb development. Annu. Rev. Cell Dev. Biol., 17:87-132, 2001.

Carlson B. Desarrollo de los miembros. En: Embriología Humana y Biología del Desarrollo. $2^{\circ}$ ed. Madrid, Editorial Elsevier, 2003. pp.189-213.

Coates, M. I. Fish fins or tetrapod limbs - a simple twist of fate? Curr. Biol., 5:844-8, 1995.

Dahn, R. D.; Davis, M. C.; Pappano, W. N. \& Shubin, N. H. Sonic hedgehog function in chondrycthyan fins and the evolution of appendage patterning. Nature, 445:311-4, 2007.

Gilbert, S. Desarrollo del miembro en los tetrápodos. En: Biología del Desarrollo. $7^{\text {a }}$ Edición. Buenos Aires, Editorial Médica Panamericana, 2006. pp. 559-84.

Haines, L. \& Currie, P. Morphogenesis and evolution of vertebrate appendicular muscle. J. Anat., 199:205-209, 2001.

Hinchliffe, J. Developmental basis of limb evolution. Int. J. Dev. Biol., 46:835-45, 2002.

Kardong, K. Vertebrates: Comparative Anatomy, Function, Evolution. $4^{\circ}$ ed. McGraw - Hill Editorial, 2005.

Kawakami, Y.; Capdevila, J.; Büscher, D.; Itoh, T.; Rodríguez
Esteban, C. \& Izpisúa Belmonte, J. C. WNT signals Control FGF-dependent limb initiation and AER Induction in the chick embryo. Cell, 104:891-900, 2001.

Kmita, M.; Tarchini, B.; Zàkàny, J.; Logan, M.; Tabin, C. J. \& Duboule, D. Early developmental arrest of mammalian limbs lacking HoxA/HoxD gene function. Nature, 435:1113-6, 2005.

Krause, A.; Zacharias, W.; Camarata, T.; Linkhart, B.; Law, E.; Lischke, A.; Miljan, E. \& Simona, H. G. Tbx5 and Tbx4 transcription factors interact with a new chicken PDZ-LIM protein in limb and heart development. Dev. Biol., 273:10620, 2004.

Loomis, C.; Harris, E.; Michaud, J.; Wurst, W.; Hanks, M. \& Joyner, A. L. The mouse Engrailed-1 gene and ventral limb patterning. Nature, 382:360-3, 1996.

Martin, A. The phylogenetic placement of Chondrichthyes: inferences from analysis of multiple genes and implications for comparative studies. Genetica. 111:349$57,2001$.

McGlinn, E. \& Tabin, C. J. Mechanistic insight into how Shh patterns the vertebrate limb. Curr. Opin. Genet. Dev., 16:42632, 2006.

Metscher, B.; Takahashi, K.; Crow, K.; Amemiya, C.; Nonaka, D. \& Wagner, G. Expression of Hoxa-11 and Hoxa-13 in the pectoral fin of a basal ray-finned fish, Polyodon spathula: implications for the origins of tetrapod limbs. Evol. Deve., 7(3):186-95, 2005. 
Montero, J. A. \& Hurlé, J. M. Deconstructing digit chondrogenesis. Bioessays, 29:725-37, 2007.

Ohuchi, H.; Nakagawa, T.; Yamamoto, A.; Araga, A.; Ohata, T.; Ishimaru, Y.; Yoshioka, H.; Kuwana, T.; Nohno, T.; Yamasaki, M.; Itoh, N. \& Noji, S. The mesenchymal factor, FGF10, initiates and maintains the outgrowth of the chick limb bud through interaction with FGF8, an apical ectodermal factor. Development, 124:2235-44, 1997.

Shum, L.; Coleman, C.; Hatakeyama, Y. \& Tuan R. Morphogenesis and dysmophogenesis of the appendicular skeleton. Birth Defects Res. Part C, 69:102-22, 2003.

Tanaka, M.; Münsterberg, A.; Anderson, W. G.; Prescott, A.; Hazon, N. \& Tickle, C. Fin development in a cartilaginous fish and the origin of vertebrate limbs. Nature, 416:527-31, 2002 .

Wassersug, R. J. A procedure for differential staining of cartilage and bone in whole formalin fixed vertebrates. Stain. Technol., 51:131-4, 1976.

Yang, Y.; Drossopoulou, G.; Chuang, P. T.; Duprez, D.; Marti, E.; Bumcrot, D.; Vargesson, N.; Clarke, J.; Niswander, L.; McMahon, A. \& Tickle, C. Relationship between dose, distance and time in Sonic Hedgehog-mediated regulation of anteroposterior polarity in the chick limb. Development, 124:4393-404, 1997.

Zakany, J. \& Duboule, D. The role of Hox genes during vertebrate limb development. Curr. Opin. Gen. Dev., 17:359-66, 2007.

Zeller, R.; López-Ríos J. \& Zuniga, A. Vertebrate limb bud development: moving towards integrative analysis of organogénesis. Nat. Rev. Gen., 10:845-58, 2009.

\author{
Dirección para correspondencia: \\ Dra. Mariana Rojas R. \\ Laboratorio de Embriología Comparada \\ Programa de Anatomía y Biología del Desarrollo \\ Facultad de Medicina, ICBM, \\ Universidad de Chile \\ Santiago \\ CHILE
}

Email: dramrojas@hotmail.com

Recibido : 17-04-2012

Aceptado: 28-06-2012 